\title{
OPEN Variability in time to surgery for patients with acute thoracolumbar spinal cord injuries
}

\author{
Jetan H. Badhiwala ${ }^{1}$, Gerald Lebovic ${ }^{2,3}$, Michael Balas ${ }^{1}$, Leodante da Costa ${ }^{1,4,5}$, \\ Avery B. Nathens S $^{3,5,6,7}$, Michael G. Fehlings ${ }^{1,4,8}$, Jefferson R. Wilson ${ }^{1,2,3,4} \&$ \\ Christopher D. Witiw ${ }^{1,2,3,4 凶}$
}

There are limited data pertaining to current practices in timing of surgical decompression for acute thoracolumbar spinal cord injury $(\mathrm{SCl})$. We conducted a retrospective cohort study to evaluate variability in timing between- and within-trauma centers in North America; and to identify patientand hospital-level factors associated with treatment delay. Adults with acute thoracolumbar $\mathrm{SCl}$ who underwent decompressive surgery within five days of injury at participating trauma centers in the American College of Surgeons Trauma Quality Improvement Program were included. Mixed-effects regression with a random intercept for trauma center was used to model the outcome of time to surgical decompression and assess risk-adjusted variability in surgery timeliness across centers. 3,948 patients admitted to 214 TQIP centers were eligible. 28 centers were outliers, with a significantly shorter or longer time to surgery than average. Case-mix and hospital characteristics explained $<1 \%$ of between-hospital variability in surgical timing. Moreover, only $7 \%$ of surgical timing variability withincenters was explained by case-mix characteristics. The adjusted intraclass correlation coefficient of $12 \%$ suggested poor correlation of surgical timing for patients with similar characteristics treated at the same center. These findings support the need for further research into the optimal timing of surgical intervention for thoracolumbar SCl.

Acute spinal cord injury (SCI) is a devastating condition that exerts a significant physical, mental, and economic burden on patients, caregivers, and society at large $\mathrm{e}^{1,2}$. While there is robust clinical evidence to support superior neurological outcomes with early $(<24 \mathrm{~h})$ compared to late $(\geq 24 \mathrm{~h})$ decompression for cervical SCI, the efficacy of early decompressive surgery in the setting of thoracolumbar SCI remains a critical knowledge gap ${ }^{3-6}$. Thoracolumbar injuries have distinct biomechanical and physiological characteristics; most notably, these injuries often result from higher energy mechanisms, and the tenuous vascular supply to the spinal cord in this region may lead to less potential for recovery ${ }^{7,8}$. The natural history of complete thoracolumbar SCI has been thought to involve negligible recovery, which has made it the target of novel experimental therapeutics ${ }^{8-11}$.

In addition to the relative equipoise in timing of decompression for patients with acute thoracolumbar SCI, there can be several barriers to urgent spinal surgical intervention in this population. At the patient-level, individuals with a thoracolumbar SCI often have concomitant chest, abdominal, pelvic, and/or extremity injuries, which may themselves necessitate intervention ${ }^{12,13}$. Further, the hemodynamic status of the patient may be prohibitive $^{14,15}$. At the hospital level, physician decision-making, institutional policies, and resource allocation are likely to influence intervention ${ }^{16}$.

Overall, there is little agreement on what constitutes an optimal threshold for surgical timing for a patient with a thoracolumbar SCI. Thresholds used in previous studies range from 8 to $72 \mathrm{~h}^{17-23}$. There is hence likely to be substantial variability, both between and within trauma centers, with regard to timing of surgical decompression.

\footnotetext{
${ }^{1}$ Division of Neurosurgery, Department of Surgery, University of Toronto, Toronto, ON, Canada. ${ }^{2}$ Li Ka Shing Knowledge Institute, St. Michael's Hospital, 30 Bond Street, TorontoToronto, ON M5W 1W8, Canada. ${ }^{3}$ Institute of Health Policy Management and Evaluation, University of Toronto, Toronto, ON, Canada. ${ }^{4}$ Spine Program, Department of Surgery, University of Toronto, Toronto, ON, Canada. ${ }^{5}$ Sunnybrook Research Institute, Sunnybrook Healthsciences Center, 2075 Bayview Avenue, Toronto, ON M4N 3M5, Canada. ${ }^{6}$ Division of General Surgery, Department of Surgery, University of Toronto, Toronto, ON, Canada. ${ }^{7}$ Medical Director, Trauma Quality Improvement Program, American College of Surgeons, Chicago, IL, USA. ${ }^{8}$ Spine Program, Krembil Brain Institute, Toronto Western Hospital, 399 Bathurst St, Toronto, ON M5T 2S8, Canada. ${ }^{凶}$ email: christopher.witiw@ unityhealth.to
} 
To that end, in patients with thoracolumbar SCI, this study aimed to (1) identify patient- and hospital-level factors independently associated with timing of surgical decompression; and (2) estimate variability in time to decompressive surgery between and within trauma centers. Rather than a survey of physician preferences, this study provides a snapshot of actual current practice at trauma centers across North America.

\section{Materials and methods}

Data source. Data were derived from the American College of Surgeons (ACS) Trauma Quality Improvement Program (TQIP) database for 2010 to $2016^{24,25}$. TQIP collects data from more than 450 ACS- and stateverified level I and II trauma centers across the United States and Canada. Patients with at least one severe injury (Abbreviated Injury Scale [AIS] $\geq 3$ in at least one body region) are included. Quality and reliability of the data are ensured through rigorous training of data abstractors and inter-rater reliability audits of participating sites.

Subjects. Adult patients ( $\geq 16$ years) who underwent surgical decompression for acute thoracolumbar SCI due to blunt trauma were eligible. Patients with a diagnosis of acute cervical or thoracolumbar SCI were first identified using Abbreviated Injury Scale (AIS) codes (Supplementary Table 1). Surgical procedures were identified using International Classification of Diseases, 9th/10th revision, Procedure Classification System (ICD-9PCS and ICD-10-PCS) codes specifying spinal decompression and/or fusion (Supplementary Table 2). Patients were excluded if: (1) they had a non-survivable injury in any body region (AIS 6); (2) they had a cervical SCI; (3) they suffered penetrating trauma; (4) they did not undergo spinal surgical decompression; or (5) they underwent spinal surgical intervention more than 5 days after injury. The threshold of 5 days corresponds to the 90th percentile for time to surgery and was selected because prolonged wait times beyond this may be attributable to non-modifiable patient factors rather than modifiable system/quality factors. Further, patients treated at trauma centers with fewer than 5 patients meeting the above criteria over the study period were excluded. This study was approved by the Sunnybrook Health Sciences Center research ethics board (Toronto, Ontario, Canada), and all methods were carried out in accordance with relevant guidelines and regulations. This study used only de-identified retrospective patient data, and individual participant informed consent was waived by the research ethics board. All methods were carried out in accordance with STROBE guidelines and regulations.

Patient-and Hospital-level characteristics. Patient demographic characteristics included age, sex, race, insurance type, and comorbidities. Comorbid status was evaluated by a modified Charlson Comorbidity Index (mCCI) (Supplementary Table 3). Injury characteristics included mechanism of injury, completeness of neurological injury, AIS score from each body region, total Injury Severity Score (ISS), and year of injury. Presenting emergency department (ED) characteristics included need for assisted ventilation, hypotension (systolic blood pressure $[\mathrm{SBP}]<90 \mathrm{mmHg}$ ), Glasgow Coma Scale (GCS) score, positive test for alcohol or other drug, and whether the patient was transferred from another institution. Hospital characteristics included geographic region, trauma center level, number of beds, teaching status, and volume (i.e., number of cases treated per year that fulfilled eligibility criteria for inclusion in the present study).

Outcomes. The primary outcome was time to decompression, defined as hours elapsed from ED arrival to first spinal surgical intervention.

Statistical analysis. All statistical analyses were performed using R version 3.5.0 (R Foundation for Statistical Computing, Vienna, Austria) with an a priori specified significance level of $P=0.05$ (two-tailed). Descriptive statistics were by mean and standard deviation (SD) or median and interquartile range (IQR) for continuous variables and count and percentage for categorical variables.

A hierarchical multi-level mixed-effects regression model was constructed with time to surgical decompression as the outcome. Fixed-effect covariates were specified for patient-level demographic, injury, and presenting ED characteristics, including age, sex, race, insurance type, comorbidities, mechanism of injury, AIS score from each body region, ISS, GCS, need for assisted respiration, hypotension, transfer status, positive alcohol test, positive drug test, year of injury, as well as hospital-level variables, including trauma center level, number of beds, teaching status, and volume (number of cases treated per year). A random-effect term was specified to account for clustering of patients within individual trauma centers. Missing data were not imputed and modelling was performed by 'complete case analysis'.

Factors associated with time to surgical decompression. The fixed-effects output of the hierarchical regression model was used to test the independent association of baseline factors with time to surgical decompression, adjusting for patient- and hospital-level confounders. Effect sizes were summarized by mean differences (MDs), and associated bootstrapped $95 \%$ confidence intervals (CIs), as residuals violated the normaility assumption.

Variability in practice patterns of time to surgical decompression. Variability across trauma centers in the timing of decompression, adjusting for individual case-mix and hospital characteristics, was evaluated using the random-effects output of the multi-level regression model. Each hospital's unique risk-adjusted MD and associated $95 \%$ CI for time to surgical decompression was derived from the model, and outliers were identified. A 'low outlier' (i.e., significantly shorter time to decompressive surgery than average) was a hospital where the upper limit of the $95 \%$ CI fell below 0 . By contrast, a 'high outlier' (i.e., significantly longer time to decompressive surgery than average) was a hospital where the lower limit of the $95 \%$ CI was greater than 0 . 
Next we determined the extent that variability in surgical timing resulted from differences in hospital casemix and characteristics. To this end, we compared the aforementioned 'full model', which included fixed-effect covariates for case-mix and hospital characteristics with a 'null model' that contained no explanatory variables. The difference in hospital-level variance between the 'full model' $\left(\mathrm{V}_{\mathrm{H} \text { full }}\right)$ and the 'null model' $\left(\mathrm{V}_{\mathrm{H} \text { null }}\right)$ represents the variability between hospitals in timeliness of surgery that is attributable to the case-mix and hospital characteristics $^{26}$. This proportional change in variance (PCV) at the hospital level is reported as the hospital $\operatorname{PCV}\left(\mathrm{PCV}_{\mathrm{H}}\right)$ (Eq. 1).

$$
P C V_{H}=\frac{V_{H \text { null }}-V_{H \text { full }}}{V_{H \text { null }}}
$$

The effect of individual characteristics on within-hospital variability in surgical timing was determined by calculating the difference in individual-level variance between the 'full model' $\left(\mathrm{V}_{\mathrm{I}}\right.$ full $)$ and the 'null model' $\left(\mathrm{V}_{\mathrm{I} \text { null }}\right)^{26}$. This PCV at the individual level is reported as the individual PCV (PCV $)$ (Eq. 2).

$$
P C V_{I}=\frac{V_{I \text { null }}-V_{\text {I full }}}{V_{I \text { null }}}
$$

Finally, the adjusted intraclass correlation coefficient (ICC) was used to measure the degree to which time to surgical decompression was contingent upon the individual hospital ${ }^{26,27}$. The adjusted ICC can be interpreted as the expected correlation in time to surgical decompression between two randomly drawn patients with similar characteristics treated at the same trauma center; or in other words, the proportion of total variance in surgical timing that remains at the hospital level after taking into account the individual patient composition and characteristics of the hospital. This is calculated using the individual-level $\left(\mathrm{V}_{\mathrm{I}}\right.$ full $)$ and hospital-level variance ( $\mathrm{V}_{\mathrm{H} \text { full }}$ ) from the 'full model' (Eq. 3).

$$
I C C_{\text {Adj }}=\frac{V_{H \text { full }}}{V_{H \text { full }}+V_{I \text { full }}}
$$

\section{Results}

Study Population. Within the TQIP database for 2010-2016, there were 4,305 patients from 372 different trauma centers with survivable injuries who underwent surgical decompression for thoracoluimbar SCI due to blunt trauma within 5 days of injury (Supplementary Fig. 1). A total of 158 centers (357 patients) that treated fewer than 5 patients meeting eligibility criteria over the study period were excluded. The final study cohort hence consisted of 3,948 patients treated at 214 individual trauma centers. Baseline characteristics are summarized in Table 1. Mean age was 39.2 years and there were 2,995 (75.9\%) males. The majority of patients were injured in a motor vehicle collision (MVC) $(n=2,234,56.6 \%)$ or fall $(n=1,323,33.5 \%)$. Mean time to surgical decompression was $28.5 \mathrm{~h}$ (median $18.8 \mathrm{~h}$ ). The cumulative percentage of patients undergoing decompression at each time point from ED arrival is plotted in Supplementary Fig. 2.

Factors associated with time to surgical decompression. Results from the hierarchical multi-level mixed-effects regression model for time to surgical decompression are summarized in Table 2 and Fig. 1. Patientlevel covariates significantly associated with longer time to decompressive surgery included older age (MD 0.18); black (MD 4.23) or Asian (MD 8.91) compared to white race; severe thorax (MD 3.51), abdomen (MD 6.63), or lower extremity (MD 4.75) injury; and hypotension (MD 4.38) or altered level of consciousness (GCS 13-14 [MD 4.38]; GCS 9-12 [MD 9.13]; GCS 3-8 [MD 9.85]) in the ED. By contrast, after 2010, each subsequent year was associated with an incrementally shorter time to surgical decompression. No center-level covariate was a significant factor in influencing time to surgical decompression.

Variability in practice patterns of time to surgical decompression. Figure 2 plots each trauma center's unique risk-adjusted mean difference for time to surgical decompression based on the random-effects output of the hierarchical multi-level mixed-effects regression model. After adjustment for case-mix and hospital-level variables, 11 hospitals were found to be low outliers, with significantly shorter time to decompressive surgery than average; by contrast, another 17 hospitals were high outliers, with significantly longer time to decompressive surgery than average. The hospital PCV between the 'null model' and the 'full model' was only $0.8 \%$, indicating the case-mix and hospital characteristics included in the full model explained less than $1 \%$ of the variability between hospitals in time to surgery (Table 3). The individual PCV was $7.4 \%$, suggesting individual case characteristics explained about $8 \%$ of the variability in time to surgery within patients at the same hospital. The adjusted ICC was $12.5 \%$, indicating rather poor correlation in time to decompression between two similar patients treated at the same trauma center (Table 3). When hospitals were grouped into quintiles based on their risk-adjusted MD for time to surgical decompression, significant differences in mean time to surgery were noted. The 828 patients across the 42 hospitals in the 1st quintile had a mean time to surgery of $16.1 \pm 17.9 \mathrm{~h}$, while the 886 patients across the 42 hospitals in the 5th quintile had a mean surgical time of $41.8 \pm 31.4 \mathrm{~h}$.

\section{Discussion}

The rationale for early surgery after acute SCI is that the expeditious relief of mechanical compression to the spinal cord may mitigate the degree of secondary neurological injury in order to afford better long-term recovery ${ }^{3,28}$. There is strong basic science data derived from rodent models of SCI to indicate superior neurobehavioral 


\begin{tabular}{|c|c|}
\hline \multicolumn{2}{|l|}{ Demographic characteristics } \\
\hline Age (yrs) - mean $\pm S D$ & $39.2 \pm 16.9$ \\
\hline Male $-n(\%)$ & $2,995(75.9)$ \\
\hline \multicolumn{2}{|l|}{ Race-n $(\%)$} \\
\hline White & $2,954(74.8)$ \\
\hline Black & $369(9.3)$ \\
\hline Asian & $59(1.5)$ \\
\hline Other & $382(9.7)$ \\
\hline Unknown & $184(4.7)$ \\
\hline \multicolumn{2}{|l|}{ Insurance- $n(\%)$} \\
\hline Government & $1,149(29.1)$ \\
\hline Private & $2,429(61.5)$ \\
\hline Other & $370(9.4)$ \\
\hline \multicolumn{2}{|l|}{ Modified Charlson Comorbidity Index-n (\%) } \\
\hline 0 & $2,587(66.1)$ \\
\hline 1 & $640(16.3)$ \\
\hline $2-3$ & $530(13.5)$ \\
\hline$>3$ & $158(4.0)$ \\
\hline \multicolumn{2}{|l|}{ Injury/Presentation characteristics } \\
\hline \multicolumn{2}{|l|}{ Mechanism of injury-n(\%) } \\
\hline MVC & $2,234(56.6)$ \\
\hline Fall & $1,323(33.5)$ \\
\hline Pedestrian/bicyclist & $194(4.9)$ \\
\hline Struck by object & $156(4.0)$ \\
\hline Other/Unknown & $37(0.9)$ \\
\hline \multicolumn{2}{|l|}{ Completeness of neurological injury $-n(\%)$} \\
\hline Complete & $2,406(60.9)$ \\
\hline Incomplete & $1,542(39.1)$ \\
\hline \multicolumn{2}{|l|}{ Severe injury $(A I S \geq 3)-n(\%)$} \\
\hline Head & $682(17.3)$ \\
\hline Face & $19(0.5)$ \\
\hline Neck & $43(1.1)$ \\
\hline Thorax & $2,313(58.6)$ \\
\hline Abdomen & $320(8.1)$ \\
\hline Spine & $3,948(100.0)$ \\
\hline Upper extremities & $94(2.4)$ \\
\hline Lower extremities & $354(9.0)$ \\
\hline Unspecified & $2(0.05)$ \\
\hline ISS $\geq 16-n(\%)$ & $3,884(99.1)$ \\
\hline \multicolumn{2}{|l|}{$G C S-n(\%)$} \\
\hline 15 & $2,934(75.5)$ \\
\hline $13-14$ & $447(11.5)$ \\
\hline $9-12$ & $128(3.3)$ \\
\hline $3-8$ & $375(9.7)$ \\
\hline Assisted ventilation in $\mathrm{ED}-n(\%)$ & $399(10.1)$ \\
\hline Hypotension in ED $(\mathrm{SBP}<90)-n(\%)$ & $313(8.0)$ \\
\hline Transferred from another institution $-n(\%)$ & $1,188(30.1)$ \\
\hline Positive alcohol test- $n(\%)$ & $809(20.5)$ \\
\hline Positive drug test $-n(\%)$ & $926(23.5)$ \\
\hline \multicolumn{2}{|l|}{ Year-n $(\%)$} \\
\hline 2010 & $335(8.5)$ \\
\hline 2011 & $424(10.7)$ \\
\hline 2012 & $534(13.5)$ \\
\hline 2013 & $589(14.9)$ \\
\hline 2014 & $696(17.6)$ \\
\hline 2015 & $721(18.3)$ \\
\hline 2016 & $649(16.4)$ \\
\hline
\end{tabular}




\begin{tabular}{|c|c|}
\hline \multicolumn{2}{|l|}{ Treatment characteristics } \\
\hline Time to surgical decompression (hrs) - mean \pm SD & $28.5 \pm 27.3$ \\
\hline \multicolumn{2}{|l|}{ Hospital characteristics } \\
\hline \multicolumn{2}{|l|}{ Region-n (\%) } \\
\hline Midwest & $794(22.4)$ \\
\hline Northeast & $397(11.2)$ \\
\hline South & $1,513(42.8)$ \\
\hline West & $835(23.6)$ \\
\hline Level I trauma center-n (\%) & $3,157(80.0)$ \\
\hline \multicolumn{2}{|l|}{ No. of beds-n(\%) } \\
\hline$>500$ & $1,989(50.4)$ \\
\hline $251-500$ & $1,659(42.0)$ \\
\hline$\leq 250$ & $300(7.6)$ \\
\hline \multicolumn{2}{|l|}{ Teaching status-n $(\%)$} \\
\hline Community & $1,115(28.2)$ \\
\hline Non-teaching & $243(6.2)$ \\
\hline University & $2,590(65.6)$ \\
\hline Volume (no. of cases per year)_-median (IQR) & $4.5(2.6-7.3)$ \\
\hline
\end{tabular}

Table 1. Baseline characteristics of study cohort. MVC Motor Vehicle Collision; ISS Injury Severity Score; GCS Glasgow Coma Scale; ED Emergency Department; SBP Systolic Blood Pressure.

outcomes when the time from injury to decompression is minimized ${ }^{29-33}$. The highest quality clinical study to date on this topic is the Surgical Timing in Acute Spinal Cord Injury Study (STASCIS), which found early surgery, within $24 \mathrm{~h}$ of injury, to be associated with a greater odds of achieving a 2-or-more grade improvement in American Spinal Injury Association (ASIA) Impairment Scale (AIS) in patients with acute cervical SCI. However, the clinical data pertaining to the effect of time to surgery for acute thoracolumbar SCI are more limited, with mixed results being derived from smaller, lower quality studies. A randomized trial of 35 patients with thoracolumbar SCI demonstrated no differences in AIS grade or motor score improvement at 12 months with early $(<24 \mathrm{~h})$ compared to late $(24-72 \mathrm{~h})$ surgical decompression; however, this trial was almost certainly underpowered to detect a difference ${ }^{19}$. By contrast, a registry-based study of 86 thoracolumbar SCI patients found early surgical decompression $(<24 \mathrm{~h})$ to be associated with 7 points in additional motor recovery and $60 \%$ decreased incidence of pulmonary complications ${ }^{8}$. A recent systematic review and meta-analysis including 14 studies failed to demonstrate a significant difference in AIS grade recovery with early $(<24 \mathrm{~h})$ versus late $\left(\geq 24 \mathrm{~h}\right.$ ) surgical decompression ${ }^{22}$. Ultimately, there remains equipoise regarding the impact of time to surgical decompression in this population, which is likely to be spurring variability in practice patterns. This study sought to elucidate key factors that may be driving treatment decisions surrounding time to surgery in patients with acute thoracolumbar SCI, and moreover, to concretely quantify the variability in practice patterns between and within trauma centers in North America.

Among patient-level characteristics, older age and black or Asian race were associated with longer time to decompressive surgery. Older age has previously been associated with less aggressive treatment and longer treatment delay following acute $\mathrm{SCI}^{34}$. There are several possible reasons for this finding. First, there may be delay in recognizing older patients' generally less severe injuries. Second, older patients are more likely to require some degree of pre-operative medical optimization and a more complex management scheme. However, the fact that older age was a significant predictor of longer time to surgery in this analysis which also adjusted for comorbidities suggests that there may be some element of an age-related therapeutic bias, with less perceived urgency in appropriately working-up, and developing a treatment plan for, older patients. The effect of black or Asian race highlights that socioeconomic and sociodemographic indicators appear to influence clinical decisionmaking in patients with acute thoracolumbar SCI. There is growing recognition of racial disparities in surgical care and outcomes. Mutiple studies have suggested that patients from visible minority groups are less likely to receive surgery ${ }^{35}$. Although these studies have predominantly focused on elective, non-emergent procedures, black/minority race has also been linked to greater likelihood of receiving surgical intervention for acute spinal fractures ${ }^{36}$. Our study, similarly, suggests race may influence clinical decision-making in the emergent setting. Surgeons should be cognizant of how sociodemographic factors may shape their own and patients' attitudes and expectations during the clinical encounter.

With regard to injury-related characteristics, severe chest, abdominal, and lower extremity injury as well as hypotension or altered level of consciousness on arrival were associated with longer delay to decompressive surgery. These findings are perhaps intuitive and somewhat expected. The presence of concomitant injuries, particularly those that may lead to hemodynamic instability as well as traumatic brain injuries, would generally take precedence over the management of an acute SCI, as per standard Advanced Trauma Life Support (ATLS) protocol $^{37}$. 


\begin{tabular}{|c|c|c|c|}
\hline & MD & $95 \% \mathrm{CI}$ & P Value \\
\hline \multicolumn{4}{|l|}{ Patient-level characteristics } \\
\hline Age & 0.18 & 0.09 to 0.28 & $<0.001$ \\
\hline Male & 0.27 & -1.76 to 2.64 & 0.427 \\
\hline \multicolumn{4}{|l|}{ Race } \\
\hline White & Reference & & \\
\hline Black & 4.23 & 0.92 to 7.37 & 0.004 \\
\hline Asian & 8.91 & 1.62 to 16.06 & 0.004 \\
\hline Other & 0.89 & -2.82 to 4.15 & 0.292 \\
\hline Unknown & -3.03 & -8.94 to 1.97 & 0.143 \\
\hline \multicolumn{4}{|l|}{ Insurance } \\
\hline Government & Reference & & \\
\hline Private & -1.80 & -3.76 to 0.34 & 0.056 \\
\hline Other & -3.71 & -7.36 to 0.35 & 0.054 \\
\hline \multicolumn{4}{|l|}{ Modified Charlson Comorbidity Index } \\
\hline 0 & Reference & & \\
\hline 1 & -1.23 & -4.40 to 1.80 & 0.199 \\
\hline $2-3$ & -0.90 & -5.34 to 3.53 & 0.324 \\
\hline$>3$ & 0.64 & -5.29 to 6.84 & 0.427 \\
\hline \multicolumn{4}{|l|}{ Mechanism } \\
\hline MVC & Reference & & \\
\hline Fall & -1.61 & -3.75 to 0.37 & 0.060 \\
\hline Pedestrian/bicyclist & 0.48 & -3.88 to 4.93 & 0.401 \\
\hline Struck by object & -3.64 & -8.41 to 1.05 & 0.052 \\
\hline Other/Unknown & 1.17 & -8.12 to 10.27 & 0.408 \\
\hline \multicolumn{4}{|l|}{ Completeness of neurological injury } \\
\hline Complete & Reference & & \\
\hline Incomplete & -1.55 & -3.39 to 0.78 & 0.058 \\
\hline \multicolumn{4}{|l|}{ Severe injury (AIS $\geq 3)$} \\
\hline Head & 2.32 & -0.19 to 4.69 & 0.053 \\
\hline Neck & 1.60 & -6.76 to 9.49 & 0.351 \\
\hline Face & -0.62 & -13.98 to 13.99 & 0466 \\
\hline Thorax & 3.51 & 1.56 to 5.56 & 0.001 \\
\hline Abdomen & 6.63 & 3.51 to 10.27 & $<0.001$ \\
\hline Upper extremities & 2.92 & -2.88 to 8.40 & 0.156 \\
\hline Lower extremities & 4.75 & 1.65 to 8.10 & 0.001 \\
\hline ISS $\geq 16$ & -10.63 & -23.30 to 3.04 & 0.057 \\
\hline \multicolumn{4}{|l|}{ GCS } \\
\hline 15 & Reference & & \\
\hline $13-14$ & 4.38 & 1.39 to 7.21 & $<0.001$ \\
\hline $9-12$ & 9.13 & 4.33 to 13.91 & $<0.001$ \\
\hline $3-8$ & 9.85 & 5.09 to 14.97 & $<0.001$ \\
\hline Assisted ventilation in ED & -0.57 & -5.41 to 3.54 & 0.416 \\
\hline Hypotension in ED $(\mathrm{SBP}<90)$ & 4.38 & 0.49 to 7.87 & 0.005 \\
\hline Transferred from another institution & -1.05 & -3.39 to 1.12 & 0.146 \\
\hline Positive alcohol test & 0.19 & -2.23 to 2.67 & 0.438 \\
\hline Positive drug test & -0.40 & -2.63 to 1.77 & 0.359 \\
\hline \multicolumn{4}{|l|}{ Year } \\
\hline 2010 & Reference & & \\
\hline 2011 & -7.31 & -12.12 to -2.86 & $<0.001$ \\
\hline 2012 & -7.48 & -12.04 to -3.09 & $<0.001$ \\
\hline 2013 & -7.49 & -12.10 to -2.71 & $<0.001$ \\
\hline 2014 & -10.47 & -14.59 to -6.39 & $<0.001$ \\
\hline 2015 & -10.95 & -15.70 to -6.39 & $<0.001$ \\
\hline 2016 & -11.47 & -16.19 to -6.90 & $<0.001$ \\
\hline \multicolumn{4}{|l|}{ Hospital-level characteristics } \\
\hline Level I trauma center & -2.32 & -7.01 to 1.81 & 0.154 \\
\hline \multicolumn{4}{|l|}{ Continued } \\
\hline
\end{tabular}




\begin{tabular}{|c|c|c|c|}
\hline & MD & $95 \% \mathrm{CI}$ & P Value \\
\hline \multicolumn{4}{|l|}{ No. of beds } \\
\hline$>500$ & Reference & & \\
\hline $251-500$ & 0.45 & -2.49 to 3.89 & 0.389 \\
\hline$\leq 250$ & -2.38 & -8.02 to 3.18 & 0.214 \\
\hline \multicolumn{4}{|l|}{ Teaching status } \\
\hline Community & Reference & & \\
\hline Non-teaching & -0.71 & -7.13 to 5.27 & 0.409 \\
\hline University & -0.49 & -4.16 to 3.27 & 0.404 \\
\hline No. of cases per year & -0.39 & -0.90 to 0.18 & 0.091 \\
\hline
\end{tabular}

Table 2. Association of patient- and hospital-level characteristics with timing of surgical decompression for acute thoracolumbar SCI. MVC Motor Vehicle Collision; ISS Injury Severity Score; GCS Glasgow Coma Scale; ED Emergency Department; SBP Systolic Blood Pressure.

Interestingly, incrementally shorter times to decompressive surgery were observed for each year subsequent to 2010. This likely reflects a shift in treatment paradigms for spinal cord injury and growing recognition of the role of early decompressive surgery with the emergence of more recent clinical evidence ${ }^{6,20,38,39}$.

In addition to identifying factors driving variability in timing of surgical decompression for acute thoracolumbar SCI, this study provides an analysis of the degree of variability in practice patterns between and within trauma centers. Twenty-eight hospitals were low or high outliers, with substantially shorter or longer time to decompressive surgery than average. Case-mix and hospital characteristics explained less than $1 \%$ of the variability in surgical timing between hospitals. This suggests that these factors are not the explaination for why certainly hospitals have substantially longer time to surgery than others. Moreover, less than $8 \%$ the variability in surgical timing within hospitals was attributable to individual patient characteristics. Hence, there remains substantial differences in surgical timing from unobserved influences, both between hospitals and within hospitals. This is further illustrated by the adjusted ICC for trauma center of $12.5 \%$. This indicates a relatively poor correlation in time to surgical decompression between two similar patients treated at the same trauma center. When hospitals were grouped into quintiles based on time to surgical decompression adjusting for case-mix and hospital characteristics, the mean difference in surgical timing was over $24 \mathrm{~h}$ longer for those treated at centers in the 5th quintile compared to the 1st quintile. This again reinforces the notion that case-mix differences do not adequately account for the between-hospital variability in time to surgical intervention. Considering all these findings together, one may conclude that there exists significant variability between trauma centers with regard to timing of surgical intervention for acute thoracolumbar SCI, even after adjusting for individual case-mix. Moreover, there is also substantial unexplained variability at the patient-level within centers. This underscores the greater need for high-quality evidence and clinical practice guidelines in this domain.

This study is strengthened by the use of high-quality, audited data from over 200 trauma centers across North America, improving generalizability of the findings. Further, the large sample size of nearly 4000 patients permitted adjustmemt for a very large number of variables in our regression modelling. Nonetheless, this study does have some notable limitations. First, the hospitals included in this analysis were level I and II trauma centers; therefore, the results may not be generalizable to all institutions where patients with acute SCI are treated. Second, despite accounting for a number of important factors, certain variables that would be expected to influence the timing of decompressive surgery for acute thoracoliumbar SCI are not captured within the TQIP database and the analysis could not be adjusted for these variables; for example, grading of spinal cord injury severity beyond complete/incomplete and fracture classification ${ }^{40-42}$. Nonetheless, we were able to account for several relevant patient-, injury-, and hospital-related factors, which represent important sources of heterogeneity in this patient population. Thirdly, we did not include transport time and time spent in a referring hospital. Nearly one-third of our cohort was transferred from another institution prior to definitive surgical intervention. If the transfer time comprised a substantial proportion of time to surgery, then this unobserved time may bias the results. However, notably transfer status had no signficant effect on surgical timing in our study. Moreover, it has been previously shown that in patients with traumatic SCI, most pre-surgical time occurs between arrival at the treating hospital and arrival in the operating room ${ }^{43,44}$. Thus, it seems the probability of early surgery is not largely influenced by transfer and transport time and more likely relates to policies and practices at the treating center.

\section{Conclusion}

The timing of surgical decompression for acute thoracolumbar SCI is influenced to a small degree by patientand injury-related factors, including: age; race; severity of concomitant chest, abdominal, and lower extremity injury; and GCS and hemodynamic status on ED arrival. Nonetheless, there is substantial variability, both within and between hospitals, in the timeliness of surgery that is unexplained by patient-, injury-, and hospital-related factors. This variability underscores the need for greater and higher quality evidence and guidelines addressing the management of acute thoracolumbar SCI. 
Patient-level characteristics GCS (3-8) GCS (9-12)

Race (Asian)

Severe injury (Abdomen) Severe injury (Lower extremity) Hypotension in ED $($ SBP < 90)

GCS (13-14)

Race (Black)

Severe injury (Thorax)

Severe injury (Upper extremity) Severe injury (Head)

Severe injury (Neck)

Mechanism (Other/Unknown)

Race (Other) $\mathrm{mCCl}(>3)$

Mechanism (Pedestrian/bicyclist) Sex (Male)

Positive alcohol test Age

Positive drug test Assisted ventilation in ED Severe injury (Face) $\mathrm{mCCl}(2-3)$

Transferred from another institution $\mathrm{mCCl}(1)$

Completeness (Incomplete) Mechanism (Fall) Insurance (Private) Race (Unknown) Mechanism (Struck by object) Insurance (Other) ISS $\geq 16$

Hospital-level characteristics No. of beds (251-500) No. of cases per year Teaching status (University) Teaching status (Non-teaching) Level I trauma center No. of beds $(\leq 250)$

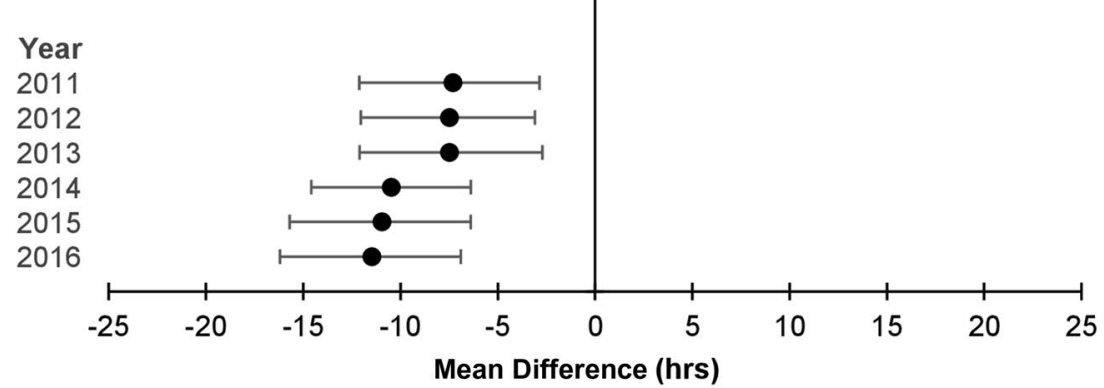

Figure 1. Forest plot of adjusted MDs and 95\% CIs for patient- and hospital-level characteristics for time to surgical decompression ${ }^{45}$. 


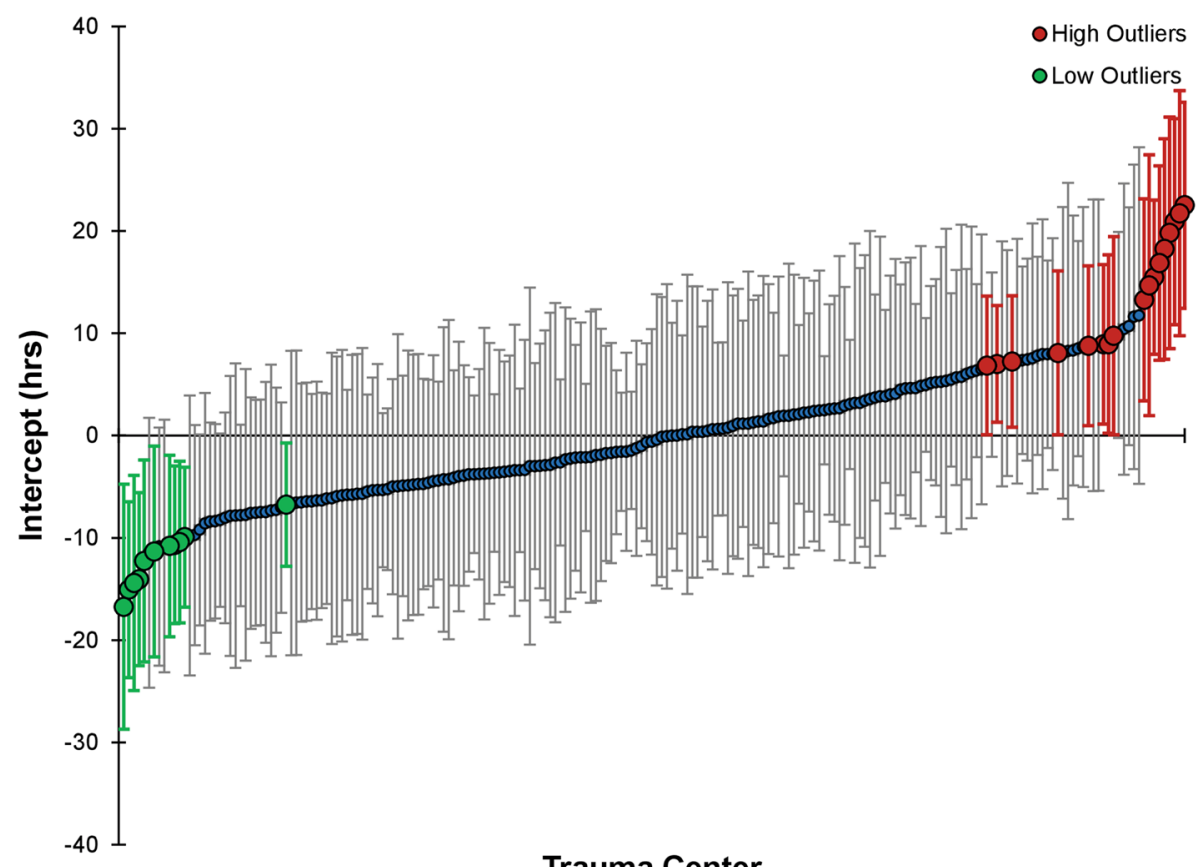

Figure 2. 'Caterpillar plot' of trauma center MDs and 95\% CIs for time to surgical decompression, risk-adjusted for patient- and hospital-level characteristics ${ }^{45}$.

\begin{tabular}{|c|c|c|}
\hline & 'Null model' & 'Full model' \\
\hline \multicolumn{3}{|l|}{ Variance components } \\
\hline Between hospitals $\left(\mathrm{V}_{\mathrm{H}}\right)$ & 87.4 & 86.7 \\
\hline Between individuals $\left(\mathrm{V}_{\mathrm{I}}\right)$ & 657.5 & 609.1 \\
\hline \multicolumn{3}{|l|}{ Proportional change in variance $(\mathrm{PCV})$} \\
\hline Between hospitals $\left(\mathrm{PCV}_{\mathrm{H}}\right)$ & reference & $0.8 \%$ \\
\hline Between individuals $\left(\mathrm{PCV}_{\mathrm{I}}\right)$ & reference & $7.4 \%$ \\
\hline Adjusted intraclass correlation $\left(\mathrm{ICC}_{\text {Adj }}\right)$ & $11.7 \%$ & $12.5 \%$ \\
\hline
\end{tabular}

Table 3. Estimates of variability in practice patterns in timing of decompression for acute thoracolumbar SCI.

\section{Data availability}

The data used for this study is available from the American College of Surgeons (ACS) Trauma Quality Improvement Program (TQIP), and may be accessed upon request to the ACS.

Received: 28 February 2021; Accepted: 8 June 2021

Published online: 25 June 2021

\section{References}

1. Badhiwala, J. H., Wilson, J. R. \& Fehlings, M. G. Global burden of traumatic brain and spinal cord injury. Lancet Neurol 18, $24-25$. https://doi.org/10.1016/S1474-4422(18)30444-7 (2019).

2. GBD 2016 Neurology Collaborators. Global, Regional, and national burden of traumatic brain injury and spinal cord injury, 1990-2016: a systematic analysis for the Global Burden of Disease Study 2016. Lancet Neurol 18, 56-87, doi: https://doi.org/10. 1016/S1474-4422(18)30415-0 (2019).

3. Badhiwala, J. H., Ahuja, C. S. \& Fehlings, M. G. Time is spine: a review of translational advances in spinal cord injury. J. Neurosurg. Spine 30, 1-18. https://doi.org/10.3171/2018.9.Spine18682 (2018).

4. Wilson, J. R. et al. Early surgery for traumatic spinal cord injury: where are we now?. Global Spine J. 10, 84s-91s. https://doi.org/ $10.1177 / 2192568219877860(2020)$.

5. Wilson, J. R. et al. Timing of decompression in patients with acute spinal cord injury: a systematic review. Global Spine J. 7, 95s-115s. https://doi.org/10.1177/2192568217701716 (2017).

6. Fehlings, M. G. et al. Early versus delayed decompression for traumatic cervical spinal cord injury: results of the surgical timing in acute spinal cord injury study (STASCIS). PLoS ONE 7, e32037. https://doi.org/10.1371/journal.pone.0032037 (2012).

7. el-Khoury, G. Y. \& Whitten, C. G. Trauma to the upper thoracic spine: anatomy, biomechanics, and unique imaging features. AJR Am. J. Roentgenol. 160, 95-102. https://doi.org/10.2214/ajr.160.1.8416656 (1993). 
8. Wilson, J. R. et al. Natural history, predictors of outcome, and effects of treatment in thoracic spinal cord injury: a multi-center cohort study from the north American clinical trials network. J. Neurotrauma 35, 2554-2560. https://doi.org/10.1089/neu.2017. 5535 (2018).

9. Saberi, H. et al. Treatment of chronic thoracic spinal cord injury patients with autologous Schwann cell transplantation: an interim report on safety considerations and possible outcomes. Neurosci Lett. 443, 46-50. https://doi.org/10.1016/j.neulet.2008.07.041 (2008).

10. Wilson, J. R., Forgione, N. \& Fehlings, M. G. Emerging therapies for acute traumatic spinal cord injury. CMAJ Canad. Med. Assoc. J. 185, 485-492. https://doi.org/10.1503/cmaj.121206 (2013).

11. Aimetti, A. A. et al. Natural history of neurological improvement following complete (AIS A) thoracic spinal cord injury across three registries to guide acute clinical trial design and interpretation. Spinal Cord 57, 753-762. https://doi.org/10.1038/s41393019-0299-8 (2019)

12. Chu, D., Lee, Y. H., Lin, C. H., Chou, P. \& Yang, N. P. Prevalence of associated injuries of spinal trauma and their effect on medical utilization among hospitalized adult subjects-a nationwide data-based study. BMC Health Serv. Res. 9, 137. https://doi.org/10. 1186/1472-6963-9-137 (2009).

13. Katsuura, Y., Osborn, J. M. \& Cason, G. W. The epidemiology of thoracolumbar trauma: a meta-analysis. J. Orthop. 13, 383-388. https://doi.org/10.1016/j.jor.2016.06.019 (2016).

14. Guly, H. R., Bouamra, O., Lecky, F. E., Trauma, A. \& Research, N. The incidence of neurogenic shock in patients with isolated spinal cord injury in the emergency department. Resuscitation 76, 57-62. https://doi.org/10.1016/j.resuscitation.2007.06.008 (2008).

15. Yue, J. K. et al. Update on critical care for acute spinal cord injury in the setting of polytrauma. Neurosurg Focus 43, E19. https:// doi.org/10.3171/2017.7.FOCUS17396 (2017).

16. Glennie, R. A. et al. An analysis of ideal and actual time to surgery after traumatic spinal cord injury in Canada. Spinal Cord 55, 618-623. https://doi.org/10.1038/sc.2016.177 (2017).

17. Cengiz, S. L., Kalkan, E., Bayir, A., Ilik, K. \& Basefer, A. Timing of thoracolomber spine stabilization in trauma patients; impact on neurological outcome and clinical course A real prospective (rct) randomized controlled study. Arch. Orthop. Trauma Surg. 128, 959-966. https://doi.org/10.1007/s00402-007-0518-1 (2008).

18. Gaebler, C., Maier, R., Kutscha-Lissberg, F., Mrkonjic, L. \& Vecsei, V. Results of spinal cord decompression and thoracolumbar pedicle stabilisation in relation to the time of operation. Spinal Cord 37, 33-39. https://doi.org/10.1038/sj.sc.3100765 (1999).

19. Rahimi-Movaghar, V. et al. Early versus late surgical decompression for traumatic thoracic/thoracolumbar (T1-L1) spinal cord injured patients Primary results of a randomized controlled trial at one year follow-up. Neurosciences (Riyadh) 19, 183-191 (2014).

20. Dvorak, M. F. et al. The influence of time from injury to surgery on motor recovery and length of hospital stay in acute traumatic spinal cord injury: an observational Canadian cohort study. J. Neurotrauma 32, 645-654. https://doi.org/10.1089/neu.2014.3632 (2015).

21. Boakye, M., Arrigo, R. T., Hayden Gephart, M. G., Zygourakis, C. C. \& Lad, S. Retrospective, propensity score-matched cohort study examining timing of fracture fixation for traumatic thoracolumbar fractures. J. Neurotrauma 29, 2220-2225. https://doi. org/10.1089/neu.2012.2364 (2012).

22. Ter Wengel, P. V. et al. Impact of early $(<24 \mathrm{~h})$ Surgical decompression on neurological recovery in thoracic spinal cord injury: a meta-analysis. J. Neurotrauma 36, 2609-2617. https://doi.org/10.1089/neu.2018.6277 (2019).

23. Eichholz, K. M. et al. Congress of neurological surgeons systematic review and evidence-based guidelines on the evaluation and treatment of patients with thoracolumbar spine trauma: timing of surgical intervention. Neurosurgery 84, E53-e55. https://doi. org/10.1093/neuros/nyy362 (2019).

24. Shafi, S. et al. The trauma quality improvement program of the American college of surgeons committee on trauma. J. Am. Coll. Surg. 209, 521-530.e521. https://doi.org/10.1016/j.jamcollsurg.2009.07.001 (2009).

25. Newgard, C. D. et al. Methodology and analytic rationale for the American college of surgeons trauma quality improvement program. J. Am. Coll. Surg. 216, 147-157. https://doi.org/10.1016/j.jamcollsurg.2012.08.017 (2013).

26. Merlo, J., Yang, M., Chaix, B., Lynch, J. \& Rastam, L. A brief conceptual tutorial on multilevel analysis in social epidemiology: investigating contextual phenomena in different groups of people. J. Epidemiol. Community Health 59, 729-736. https://doi.org/ 10.1136/jech.2004.023929 (2005)

27. McGraw, K. O. \& Wong, S. P. Forming inferences about some intraclass correlation coefficients. Psychol. Methods 1, 30-46. https:// doi.org/10.1037/1082-989X.1.4.390 (1996).

28. Ahuja, C. S. et al. Traumatic spinal cord injury. Nat. Rev. Dis. Primers. 3, 17018. https://doi.org/10.1038/nrdp.2017.18 (2017).

29. Dimar, J. R., Glassman, S. D., Raque, G. H. \& Zhang, Y. P. Shields CB (1999) The influence of spinal canal narrowing and timing of decompression on neurologic recovery after spinal cord contusion in a rat model. Spine Phila Pa 24, 1623-1633. https://doi.org/ 10.1097/00007632-199908150-00002 (1976).

30. Carlson, G. D., Gorden, C. D., Oliff, H. S., Pillai, J. J. \& LaManna, J. C. Sustained spinal cord compression: part I: time-dependent effect on long-term pathophysiology. J. Bone Joint Surg. Am. 85, 86-94 (2003).

31. Furlan, J. C., Noonan, V., Cadotte, D. W. \& Fehlings, M. G. Timing of decompressive surgery of spinal cord after traumatic spinal cord injury: an evidence-based examination of pre-clinical and clinical studies. J. Neurotrauma 28, 1371-1399. https://doi.org/ 10.1089/neu.2009.1147 (2011).

32. Guha, A., Tator, C. H., Endrenyi, L. \& Piper, I. Decompression of the spinal cord improves recovery after acute experimental spinal cord compression injury. Paraplegia 25, 324-339. https://doi.org/10.1038/sc.1987.61 (1987).

33. Batchelor, P. E. et al. Meta-analysis of pre-clinical studies of early decompression in acute spinal cord injury: a battle of time and pressure. PLoS ONE 8, e72659. https://doi.org/10.1371/journal.pone.0072659 (2013).

34. Ahn, H. et al. Effect of older age on treatment decisions and outcomes among patients with traumatic spinal cord injury. CMAJ 187, 873-880. https://doi.org/10.1503/cmaj.150085 (2015).

35. Haider, A. H. et al. Racial disparities in surgical care and outcomes in the United States: a comprehensive review of patient, provider, and systemic factors. J. Am. Coll Surg. 216, 482-492. https://doi.org/10.1016/j.jamcollsurg.2012.11.014 (2013).

36. Daly, M. C., Patel, M. S. \& Bhatia, N. N. Bederman SS (2016) The influence of insurance status on the surgical treatment of acute spinal fractures. Spine Phila Pa 41, E37-45. https://doi.org/10.1097/BRS.0000000000001177 (1976).

37. Advanced Trauma Life Support (ATLS) Student Course Manual. 9th edn, (American College of Surgeons, 2012).

38. Wilson, J. R. et al. Early versus late surgery for traumatic spinal cord injury: the results of a prospective Canadian cohort study. Spinal Cord 50, 840-843. https://doi.org/10.1038/sc.2012.59 (2012).

39. ElTecle, N. E. \& Dahdaleh, N. S. Hitchon PW (2016) Timing of surgery in spinal cord injury. Spine Phila Pa 41, E995-E1004. https://doi.org/10.1097/BRS.0000000000001517 (1976).

40. Kirshblum, S. C. et al. International standards for neurological classification of spinal cord injury (revised 2011). J. Spinal. Cord Med. 34, 535-546. https://doi.org/10.1179/204577211X13207446293695 (2011).

41. Vaccaro, A. R. et al. (2013) AOSpine thoracolumbar spine injury classification system: fracture description, neurological status, and key modifiers. Spine Phila Pa 38, 2028-2037. https://doi.org/10.1097/BRS.0b013e3182a8a381 (1976).

42. Vaccaro, A. R. et al. (2005) A new classification of thoracolumbar injuries: the importance of injury morphology, the integrity of the posterior ligamentous complex, and neurologic status. Spine Phila Pa 30, 2325-2333. https://doi.org/10.1097/01.brs.00001 82986.43345.cb (1976). 
43. Agostinello, J., Battistuzzo, C. R., Skeers, P. \& Bernard, S. Batchelor PE (2017) Early spinal surgery following thoracolumbar spinal cord injury: process of care from trauma to theater. Spine Phila Pa 42, E617-E623. https://doi.org/10.1097/brs.0000000000001903 (1976).

44. Samuel, A. M. et al. (2015) Analysis of delays to surgery for cervical spinal cord injuries. Spine Phila Pa 40, 992-1000. https://doi. org/10.1097/brs.0000000000000883 (1976).

45. R Core Team. R: a language and environment for statistical computing. R Foundation for Statistical Computing. (2020).

\section{Acknowledgements}

The authors would like to thank Melissa Tom for her assistance with database management. Avery B. Nathens is the Medical Director, Trauma Quality Programs, American College of Surgeons.

\section{Author contributions}

J.H.B. Study design, data analysis, manuscript preparation and revisions. G.L. Data analysis, manuscript preparation and revisions. M.B. Data analysis, manuscript preparation and revisions. Ld.C. Manuscript revisions. A.B.N. Data acquisition and manuscript revisions. M.G.F. Manuscript revisions. J.R.W. Manuscript revisions. C.D.W. Study design, data analysis, manuscript preparation and revisions.

\section{Funding}

This study was funded by the Young Investigator Award from AOSpine North America.

\section{Competing interests}

The authors declare no competing interests.

\section{Additional information}

Supplementary Information The online version contains supplementary material available at https://doi.org/ 10.1038/s41598-021-92310-Z.

Correspondence and requests for materials should be addressed to C.D.W.

Reprints and permissions information is available at www.nature.com/reprints.

Publisher's note Springer Nature remains neutral with regard to jurisdictional claims in published maps and institutional affiliations.

(c) (i) Open Access This article is licensed under a Creative Commons Attribution 4.0 International License, which permits use, sharing, adaptation, distribution and reproduction in any medium or format, as long as you give appropriate credit to the original author(s) and the source, provide a link to the Creative Commons licence, and indicate if changes were made. The images or other third party material in this article are included in the article's Creative Commons licence, unless indicated otherwise in a credit line to the material. If material is not included in the article's Creative Commons licence and your intended use is not permitted by statutory regulation or exceeds the permitted use, you will need to obtain permission directly from the copyright holder. To view a copy of this licence, visit http://creativecommons.org/licenses/by/4.0/.

(C) The Author(s) 2021 